\title{
Use and perceived helpfulness of smoking cessation methods: results from a population survey of recent quitters
}

\author{
Wai Tak Hung ${ }^{1 *}$, Sally M Dunlop ${ }^{2,3}$, Donna Perez ${ }^{2}$ and Trish Cotter ${ }^{2}$
}

\begin{abstract}
Background: Increasing rates of smoking cessation is one of the most effective measures available to improve population health. To advance the goal of increasing successful cessation at the population level, it is imperative that we understand more about smokers' use of cessation methods, as well as the helpfulness of those methods in real-world experiences of quitting. In this survey of recent quitters, we simultaneously examined rates of use and perceived helpfulness of various cessation methods.
\end{abstract}

Methods: Recent quitters (within 12 months; $\mathrm{n}=1097$ ) completed a telephone survey including questions relating to 13 cessation methods. Indices of use and perceived helpfulness for each method were plotted in a quadrant analysis. Socio-demographic differences were explored using bivariate and multivariate analyses.

Results: From the quadrant analysis, cold turkey, NRT and gradual reduction before quitting had high use and helpfulness; GP advice had high use and lower helpfulness. Prescribed medication and online programs had low use but high helpfulness. Remaining methods had low use and helpfulness. Younger quitters were more likely to use unassisted methods such as cold turkey; older or less educated quitters were more likely to use assisted methods such as prescribed medication or advice from a general practitioner.

Conclusions: The majority of recent quitters quit cold turkey or cut down before quitting, and reported that these methods were helpful. Efforts to influence population smoking prevalence should attempt to provide support and motivation for smokers choosing these methods, in addition to assessing the effectiveness and accessibility of other methods for smokers who need or choose them.

\section{Background}

Cigarette smoking remains the leading preventable cause of death and disease in the developed world [1,2], and increasing the number of smokers successfully quitting is one of the most effective measures available to improve population health. Cessation activity among smokers is relatively common; more than $40 \%$ of current U.S. smokers report having made a serious attempt to quit in the past 12 months [3] and in the Australian state of New South Wales (NSW) less than $20 \%$ of smokers have never tried to quit [4]. However, only about $3 \%-5 \%$ of smokers maintain abstinence up to one year after quitting [5]. To advance the goal of increasing successful cessation at the

\footnotetext{
* Correspondence: arthur.hung@cancerinstitute.org.au

'Monitoring, Evaluation and Research Unit, Cancer Institute NSW, Level 9, 8 Central Avenue, Australian Technology Park, Eveleigh NSW 2015, Australia Full list of author information is available at the end of the article
}

population level, it is imperative that we understand how smokers quit, one aspect of which is the use and helpfulness of various cessation methods and aids.

Over the last decade, numerous studies have documented the proportion of smokers using various cessation methods. In the U.S., it is estimated that around one quarter of smokers use pharmacologic treatments such as nicotine replacement therapy (NRT) and bupropion when attempting to quit $[3,6,7]$. The use of behavioural treatments is estimated to be under $8 \%[3,7]$. Among behavioural treatments, self-help material is the most commonly used, but others include individual, group and telephone counselling [3]. In NSW, the most common aid used in quit attempts is NRT (approximately 33\%), followed by bupropion (13.2\%), with very small proportions of smokers reporting that they used behavioural aids such as telephone helplines $[4,8]$. Despite the

\section{Biomed Central}

(c) 2011 Hung et al; licensee BioMed Central Ltd. This is an Open Access article distributed under the terms of the Creative Commons Attribution License (http://creativecommons.org/licenses/by/2.0), which permits unrestricted use, distribution, and reproduction in any medium, provided the original work is properly cited. 
increasing availability and marketing of pharmacological and behavioural interventions, population studies consistently show that the largest proportion of smokers who permanently quit smoking do so without any form of assistance [3,6,8-12]. That is, the most common method used by people who have successfully stopped smoking remains unassisted cessation (cold turkey or reducing before quitting).

When evaluating cessation methods, it is important to consider not just how often a cessation method is used, but also how helpful it is achieving smoking abstinence. Research investigating the effectiveness of various cessation methods and aids has fallen primarily into two categories - randomized controlled trials and retrospective population surveys. Controlled trials have generally demonstrated the efficacy of behavioural and pharmacological cessation interventions [13]. However, there has been a divergence between the findings from these trials and the results of retrospective population surveys in which smokers who report using behavioural or pharmacologic treatment are less likely to be successful in quitting $[3,8,11,14]$. Only one recent survey has indicated greater quitting success in individuals who sought assistance than those not seeking assistance [6]. Some researchers have suggested that the inconsistency between the controlled studies and population surveys may be due to selection bias, with heavier or more addicted smokers being more likely to use cessation programs $[3,6,7,11]$, and also being the most likely to relapse [15].

In the current study, using reports from recent quitters, we take into account both the reported use and perceived helpfulness of different cessation methods. In doing so, we can identify methods which have high impact - those which are used frequently and rated as helpful - as well as those which are rated as helpful, but used less frequently. The latter category could be a target for increased promotion. Conversely, identifying methods which have a low helpfulness rating could inform policy decisions and research priorities. We explore differences in use and perceived helpfulness of cessation methods by quitters who vary by socio-demographic characteristics, as well as by length of abstinence.

Throughout the study period (2007-2009), a range of quitting methods was available to smokers in Australia. A free national telephone cessation helpline (the Quitline) exists and is advertised on all cigarette packets and in media campaigns. NRT has been available over-thecounter since 1997. Bupropion $\left(\right.$ Zyban $^{\circledR}$ ) has been available since 2000 by prescription (with government subsidy since early 2001) and prescribed varenicline $\left(\right.$ Champix ${ }^{\circledR}$ ) has been available with subsidy since January 2008. Additionally, a number of community-outreach groups provide counselling and support, and web-based support is increasingly available.

\section{Method}

\section{Participants and Procedure}

Data come from the Cancer Institute NSW's Tobacco Tracking Survey (CITTS). The CITTS is a telephone survey of adult smokers and recent quitters (aged 18 years and over) which monitors smoking-related cognitions, intentions and behaviours in the community, as well as responses to tobacco control policies and ongoing anti-smoking media campaigns. Households are recruited to the telephone survey using random digit dialling and participants are recruited using a random selection procedure. Fifty interviews per week are conducted across most weeks of the year; data for this study was collected between April 2007 and December 2009. An overall response rate of $27.4 \%$ was achieved for this period (American Association for Public Opinion Research Response Rate \#4 [16]), with a total sample of 7,085 adults (both smokers and recent quitters). Weights were applied to adjust for gender, age and region, according to the NSW population [17]. Analyses for this study are limited to individuals who reported having quit smoking within the last 12 months (recent quitters, $n=1097$ ).

\section{Measures}

\section{Cessation methods}

Respondents were asked 'Did you use any of the following to help you quit smoking?'. The cessation methods that respondents were queried about were: NRT (including gum, lozenges, patches or inhalers), prescribed medication, the Quitline, online quit smoking information or programs, other 'how to quit' or 'self-help' materials, cold turkey, cutting down on the amount smoked before quitting (gradual reduction), changing to 'light' cigarettes, advice from dentist, advice from a general practitioner (GP), advice from a pharmacist, advice from another health professional, and natural or alternative therapies (e.g. hypnotherapy, acupuncture, laser therapy). Given that many smokers use one or more methods when quitting $[3,8]$, respondents could nominate multiple methods. If they answered that they used a cessation method, they were asked whether it had helped them 'a great deal', 'somewhat' or 'not at all' (dichotomised into 'at least somewhat' vs. 'not at all').

Respondents also had the opportunity to report any other aid or method they used or to state that 'none of the above' helped them. Other methods were recorded verbatim, and recoded back into the original list if appropriate. Respondents who answered that they used 'none of the above' and did not specify any other methods $(n=28)$, or answered 'don't know' $(n=1)$, were excluded from analyses (resulting weighted sample, $n=$ 1068). 


\section{Smoking and Demographic Characteristics}

Demographic items measuring age, gender and education level (grouped into high school or less vs some or completed tertiary education) were included in the survey. Respondents were asked how long ago they quit smoking ('in the last two weeks', 'in the last month', 'in the last six months', or 'in the last year'). Postcodes were used with the Socio-Economic Indices for Areas [SEIFA; [18]] to indicate socio-economic status (quintiles four and five classified as low SES, and quintiles one to three as moderate-high SES).

\section{Statistical Analyses}

First, we used a quadrant analysis to simultaneously examine the use and perceived helpfulness of each method [19]. In the quadrant analysis, an index of use for each method was plotted along the $\mathrm{x}$-axis, whilst an index of perceived helpfulness for each method was plotted on the y-axis. First, the proportion of respondents who used a particular cessation method was calculated $\left(x_{i}\right)$. Next, the overall proportion of use of any cessation method $(X)$ was obtained by calculating the weighted average of all $x_{i}$ using the corresponding sample size $\left(n_{i}\right)$ as the weight. Using a weighted average allowed for any method with a larger base sample size to have a greater contribution to the overall proportion of use. An index of use for each method was calculated by dividing $x_{i}$ by $X$ and multiplying by 100 , such that a score of 100 was the average. The index of perceived helpfulness was created similarly.

The four quadrants were thus defined: Quadrant I has methods with indices of use and perceived helpfulness both greater than or equal to 100 (high use and high helpfulness); Quadrant II has methods that have an index of use greater than or equal to 100 but an index of helpfulness less than 100 (high use and low helpfulness); Quadrant III has methods that have an index of use less than 100 but an index of helpfulness greater than or equal to 100 (low use but high helpfulness); Quadrant IV has methods with indices of use and helpfulness both less than 100 (low use and low helpfulness).

Next, we conducted bivariate analyses to determine associations between individual characteristics and use or perceived helpfulness of cessation methods, using chisquared tests or Fisher's Exact test (for two-by-two contingency tables), and assessing linear trend for age. Finally, for each of the most frequently used methods which fell into Quadrants I, II and III, separate multiple logistic regression analyses were used to predict their use and perceived helpfulness. Following Hosmer and Lemeshow's recommendations for logistic regression with a large potential set of predictors [20], individual characteristics that had at least some degree of association with the outcome variable $(p<0.2)$ were entered into a backward stepwise logistic regression to predict the outcomes of interest. Only data from respondents who had no missing data on the variables of interest were included in each analysis; missing data on demographic variables reduced sample sizes slightly below the total number of cases available (see $n$ s in tables). All analyses were performed using SPSS version 15 [21].

\section{Results}

\section{Sample Characteristics}

The final sample was 54\% female. Twenty-four percent of the sample was aged $18-30$ years, $41 \%$ were $31-50$ years, and $35 \%$ were over 50 years. Sixty-five percent of these recent quitters had been abstinent less than six months (9\% quit in the last 2 weeks; $12 \%$ in the last month; $44 \%$ more than one month ago but less than 6 months ago; $35 \%$ more than 6 months ago). Slightly fewer than half (46\%) of the sample had high school or less education, and $36 \%$ were classified as low SES.

\section{Use and Perceived Helpfulness of Cessation Methods}

Sixty-six percent of recent quitters reported that they had used one or two of the cessation methods to help them quit, and $34 \%$ had used three or more. The most frequently cited cessation method was cold turkey, with $69 \%$ of respondents reporting that they used this method. The next two most common methods were gradual reduction and NRT (both 29\%). Figure 1 shows the quadrant analysis: cold turkey, NRT and gradual reduction were in Quadrant I; GP advice was in Quadrant II; prescribed medication and online programs were in Quadrant III; and all remaining methods were in Quadrant IV.

\section{Bivariate Associations between Characteristics of Recent Quitters and Use and Perceived Helpfulness of Cessation Methods}

The use of the individual cessation methods were analysed to investigate differences by respondent characteristics (see Table 1). Use of NRT, GP advice, health professional advice, natural therapy, and prescribed medication showed a significant positive trend of age, in that use was higher among older compared to younger respondents. In contrast, gradual reduction and cold turkey showed significant negative trends for age, in that use was most common among younger respondents. Chi-squared tests showed a significant age differences for use of dentist advice and the Quitline, with highest use among the middle age group (31-50 years). Use of an online program was significantly associated with gender; more females used an online program than males, though use for both genders was low.

The use of NRT, pharmacist advice and prescribed medication were each significantly associated with quit duration; use was greater among respondents who had been abstinent six months or less compared to those 


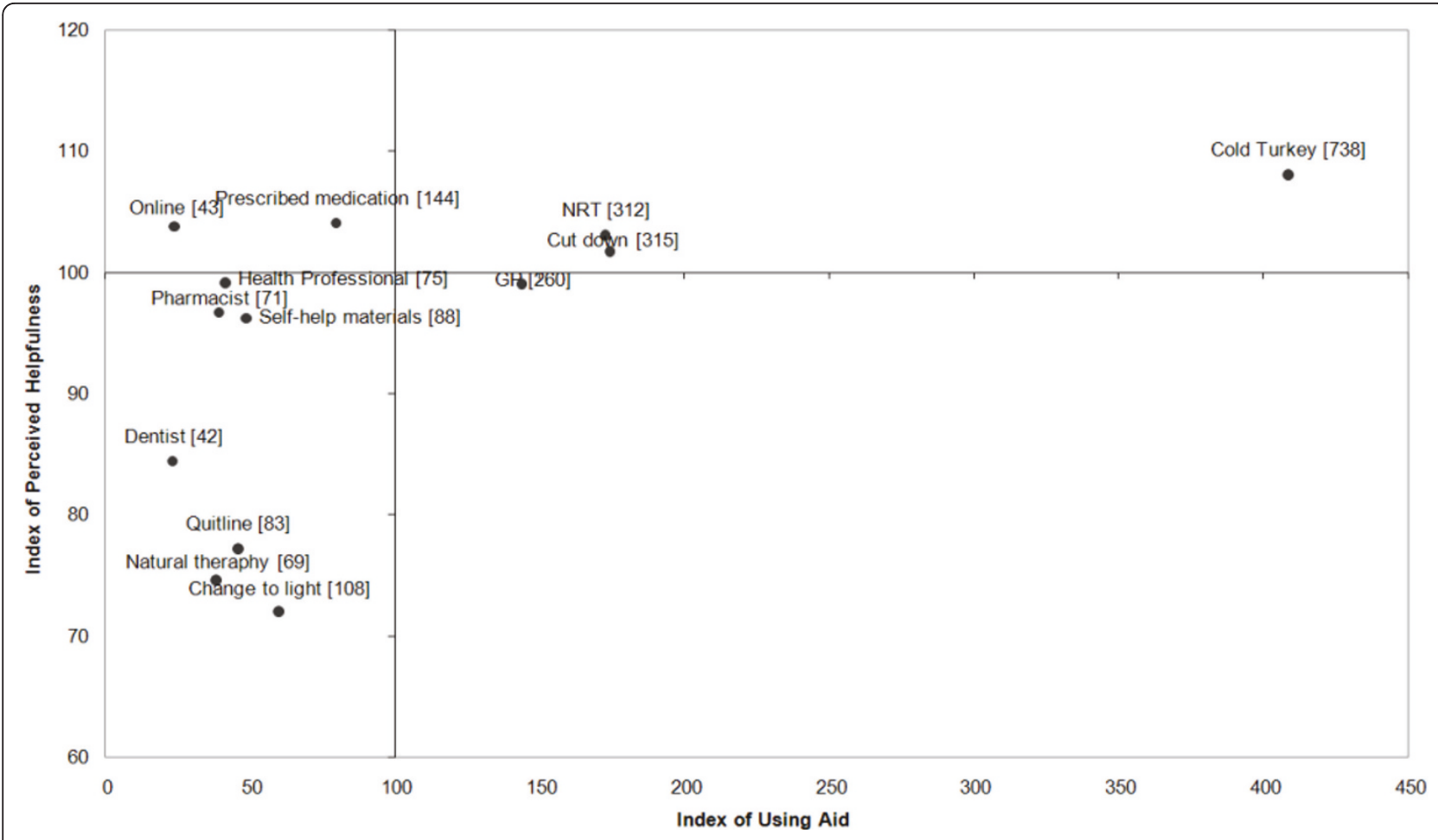

Figure 1 Quadrant analysis of different quitting methods. Note. Numbers in brackets are sample sizes for use of each method.

abstinent more than 6 months. Conversely, cold turkey was used by a significantly larger proportion of quitters who had been abstinent for more than six months. Use of GP advice and prescribed medication was higher among respondents of low SES compared to those of moderate-high SES. However, use of self-help materials and cold turkey was higher among those of moderatehigh SES compared to low SES. Use of GP advice and prescribed medication was also higher among respondents with high school or less education compared to those with tertiary education. Use of alternative therapies was higher among those with tertiary education.

We also considered differences in perceived helpfulness of each aid or method according to individual characteristics (see Table 2). For NRT and GP advice, there was a significant positive trend of age, in that a higher proportion of older respondents reported being helped by those methods compared to younger respondents. In contrast, changing to 'lights', calling the Quitline, and using online programs showed a significant negative trend of age, in that a higher proportion of younger respondents reported that these methods were helpful compared to older respondents. A higher proportion of low SES respondents reported that prescribed medication helped them compared to the moderate-high SES group. There were no associations between the helpfulness of any method and gender, quit duration, or education.
Multivariate Associations between Characteristics of Recent Quitters and Use and Helpfulness of Cessation Methods

Backwards step-wise logistic regression analyses were conducted to predict the use of cessation methods which fell into Quadrants I, II or III and had substantial sample sizes; namely, quitting cold turkey, using NRT, receiving GP advice, gradual reduction, and using prescribed medication (see Table 3). The model predicting gradual reduction showed no significant predictors, and is therefore not shown.

In the model predicting quitting cold turkey, being younger in age, having a longer quit duration, or being moderate-high SES were significant predictors. For NRT, recent quitters who were either older in age or had a shorter quit duration were more likely to report using NRT than their respective reference groups. In the model predicting use of GP advice, being less educated, older in age, or having a shorter quit duration were significant predictors. For use of prescribed medication, education, age, and quit duration were retained in the final model. This model had the same set of predictors as the model for GP advice.

When considering multivariate predictors of perceived helpfulness of the methods, only prescribed medication had more than one potential predictor $(p<.02)$. In the logistic regression analysis to predict perceived helpfulness 
Table 1 Recent quitters' use of cessation methods by socio-demographic and quitting characteristics

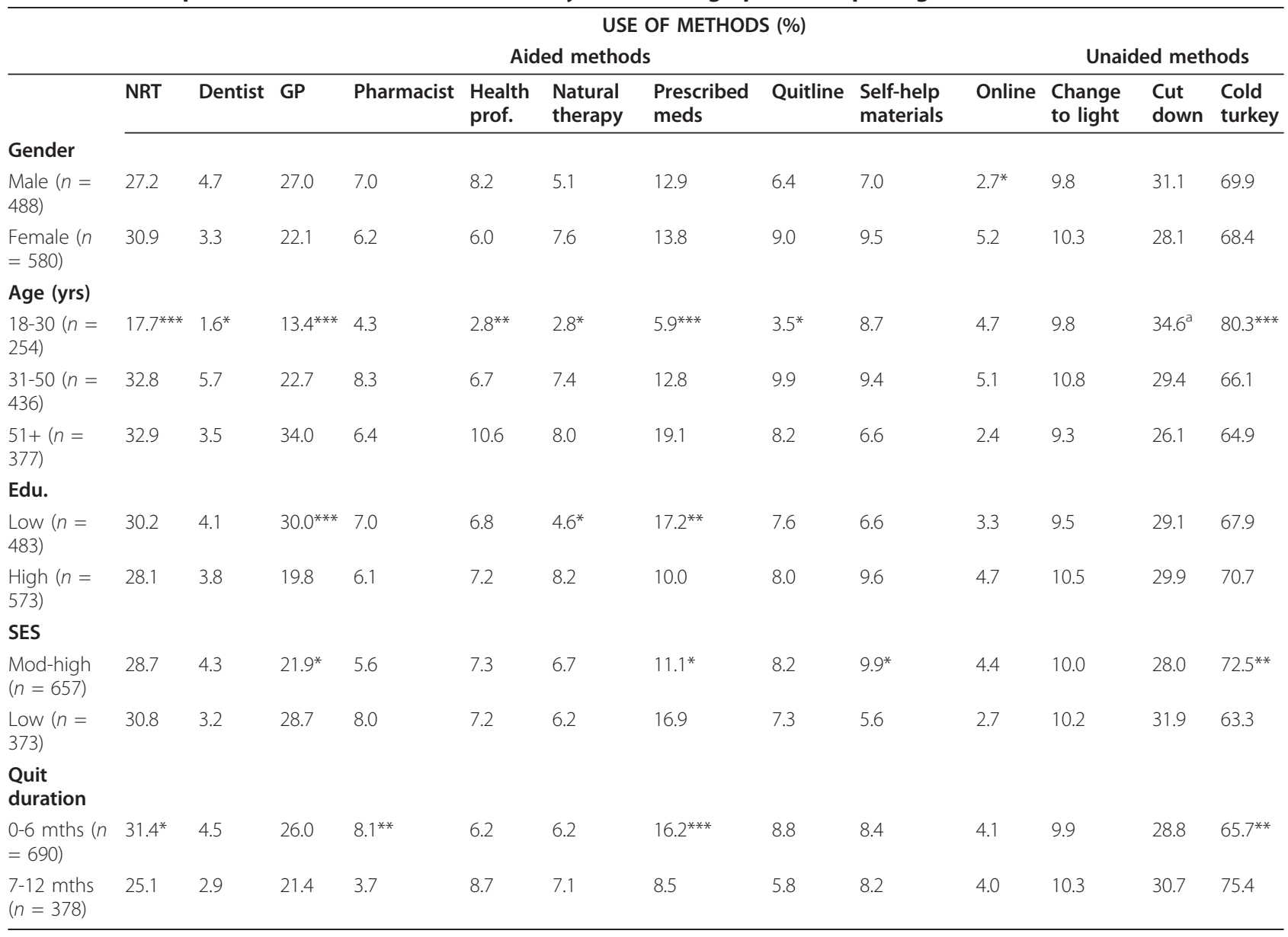

Note. Health prof $=$ Health professional advice; Edu = Education (low = less than Year 12, high = some or completed tertiary); SES = socio-economic status; statistical tests of differences between groups are chi-square or Fisher's Exact test; ${ }^{* * *} p<.001,{ }^{* *} p<.01,{ }^{*} p<0.05 ;{ }^{a}$ chi-square test not significant but linear trend $p<0.05$.

of prescribed medication, gender and SES were retained in the final model, with male quitters marginally more likely to find prescribed medication helpful than females $(\mathrm{OR}=$ 4.18, 95\% CI[0.94-18.55], $p=0.06$ ) and low SES quitters more likely to find it helpful than moderate-high SES quitters $(\mathrm{OR}=13.17,95 \% \mathrm{CI}[1.57-110.47], p=0.02)$.

\section{Discussion}

Consistent with a growing body of literature documenting that the majority of ex-smokers successfully quit without assistance, in the current study, more than two-thirds of recent quitters reported that they had used the cold turkey method to help them quit. Because this study did not explicitly ask about cessation methods used in their last quit attempt, we cannot claim that these smokers finally quit successfully using cold turkey. Nonetheless, our measure of perceived helpfulness for each of the methods provides a good indication that not only is cold turkey used by a large proportion of smokers in quitting and attempting to quit, it is also perceived as being more helpful than any other method. Research shows that smokers often make more than one attempt to quit smoking [22,23], potentially using a variety of methods either at the same time or over the course of many quit attempts [4]. In this case, the measure of perceived helpfulness is particularly useful, as it allows quitters to make a distinction between the methods that have helped them and those which have not.

Pharmacological aids such as NRT and prescribed medication were also considered helpful by most of the recent quitters who used them. However, NRT was used by less than one third of recent quitters, and prescribed medications less than that. This level of use, despite widespread promotional activity, is consistent with evidence suggesting that, as a population-based strategy, pharmacological aids are unlikely to have as great an impact on lowering smoking prevalence rates as cold turkey [24,25].

From the quadrant analysis, it was apparent that GP advice, though used relatively frequently, was rated as just below the average level of helpfulness. In 2009, 40\% 
Table 2 Recent quitters' perceived helpfulness of cessation methods by socio-demographic and quitting characteristics

\begin{tabular}{|c|c|c|c|c|c|c|c|c|c|c|c|c|c|}
\hline & \multicolumn{13}{|c|}{ PERCEIVED HELPFULNESS OF METHODS (\%) } \\
\hline & \multirow[b]{2}{*}{ NRT } & \multicolumn{9}{|c|}{ Aided methods } & \multicolumn{3}{|c|}{ Unaided methods $(\mathrm{n})$} \\
\hline & & Dentist & GP & Pharmacist & $\begin{array}{l}\text { Health } \\
\text { prof. }\end{array}$ & $\begin{array}{l}\text { Natural } \\
\text { therapy }\end{array}$ & $\begin{array}{l}\text { Prescribed } \\
\text { meds }\end{array}$ & Quitline & $\begin{array}{l}\text { Self-help } \\
\text { materials }\end{array}$ & Online & $\begin{array}{l}\text { Change } \\
\text { to light }\end{array}$ & $\begin{array}{l}\text { Cut } \\
\text { down }\end{array}$ & $\begin{array}{l}\text { Cold } \\
\text { turkey }\end{array}$ \\
\hline \multicolumn{14}{|l|}{ Gender } \\
\hline Male & 92.5 & 62.5 & 87.9 & 76.5 & 92.5 & 60.0 & 96.8 & 64.5 & 76.5 & 100.0 & 62.5 & 90.1 & 95.0 \\
\hline Female & 88.3 & 84.2 & 85.2 & 91.9 & 80.6 & 66.7 & 87.5 & 67.3 & 87.0 & 86.7 & 65.0 & 87.7 & 94.0 \\
\hline \multicolumn{14}{|l|}{ Age (yrs) } \\
\hline $18-30$ & $80.0^{*}$ & 100.0 & $70.6^{*}$ & 72.7 & 71.4 & 85.7 & 93.3 & $88.9^{a}$ & $95.5^{*}$ & $100^{* *}$ & $84.0^{*}$ & 93.2 & 96.1 \\
\hline $31-50$ & 90.9 & 79.2 & 87.9 & 86.1 & 86.2 & 68.8 & 92.9 & 72.1 & 85.4 & 95.7 & 62.5 & 88.3 & 93.4 \\
\hline $51+$ & 92.7 & 57.1 & 89.1 & 88.0 & 90.0 & 53.3 & 90.3 & 54.8 & 68.0 & 62.5 & 51.4 & 86.7 & 94.7 \\
\hline \multicolumn{14}{|l|}{ Education } \\
\hline Low & 92.5 & 80.0 & 87.6 & 91.2 & 84.8 & 50.0 & 89.3 & 72.2 & 87.9 & 81.3 & 67.4 & 87.9 & 93.3 \\
\hline High & 88.2 & 68.2 & 85.0 & 77.8 & 87.8 & 70.2 & 93.0 & 63.0 & 80.0 & 96.3 & 60.0 & 89.5 & 95.3 \\
\hline \multicolumn{14}{|l|}{ SES } \\
\hline Mod-high & 89.9 & 75.0 & 86.1 & 83.8 & 83.3 & 62.8 & $83.8^{* *}$ & 61.1 & 78.5 & 89.7 & 65.2 & 86.4 & 95.2 \\
\hline Low & 90.4 & 66.7 & 86.9 & 86.7 & 92.6 & 69.6 & 98.4 & 82.1 & 95.2 & 90.0 & 57.9 & 92.4 & 93.2 \\
\hline \multicolumn{14}{|l|}{$\begin{array}{l}\text { Quit } \\
\text { duration }\end{array}$} \\
\hline $0-6$ mths & 89.4 & 71.0 & 85.6 & 86.0 & 90.7 & 60.5 & 91.1 & 63.9 & 82.8 & 85.7 & 65.2 & 87.9 & 93.6 \\
\hline 7-12 mths & 91.5 & 81.8 & 87.7 & 78.6 & 81.8 & 70.4 & 90.6 & 77.3 & 83.9 & 100.0 & 61.5 & 90.6 & 95.8 \\
\hline
\end{tabular}

Note. Health prof $=$ Health professional advice; Edu = Education (low = less than Year 12, high = some or completed tertiary); SES $=$ socio-economic status;

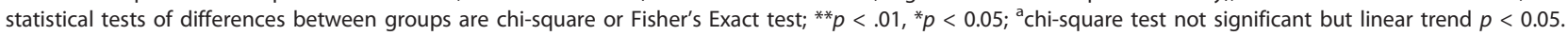

of a sample of NSW smokers had discussed their smoking on their last GP visit, and even more (63\%) were open to seeking advice from their doctor [4]. In combination, these findings confirm that physicians' perceptions of patients' disinterest in quitting [26] should not be a barrier to their engagement in cessation assistance.

From our analysis of individual characteristics associated with use of the various cessation methods, we can develop profile of quitters who used assisted method of quitting. We found that older quitters were more likely to have used GP advice or prescribed medication than younger quitters; less educated quitters were more likely to have used GP advice or prescribed medication than more educated; and individuals who had been quit for less than six months were more likely to have used NRT than those who had been quit for longer. Conversely, the quitters who reported quitting cold turkey were either younger, had been quit for longer, or were of moderate-high SES. Consistent with previous research $[3,6,7,11]$, these findings suggest that more heavily addicted smokers (based quit duration and age) are more likely to use assistance in quitting, while less addicted smokers are more likely to quit cold turkey. These quitting profiles have implications for targeted promotion of assisted cessation services and products.

Emerging research has suggested that internet-based cessation programs might be effective [27], and this is supported by the relatively high perceived helpfulness of online programs in the current study. However, the overall use of online programs was low. In a recent study, only $24 \%$ of 'quit smoking' searches ended at a professional smoking cessation website, with many searches ending at alternative therapy sites [28], perhaps indicating a paucity of accessible and effective programs. Though the numbers of younger quitters who used online programs in the current study were small, those who did were more likely than older individuals to report that they were helpful. Future research might explore ways to increase young smokers' engagement with effective online support.

This study, along with others [29-31], shows a very low utilisation rate of telephone cessation helplines. In 2009, $81 \%$ of ex-smokers and smokers who had tried to quit in NSW were aware of the Quitline but had never called it [4], suggesting that factors other than awareness might influence use of this service. The low use and perceived helpfulness of the Quitline among NSW quitters suggests that, in its current form, this mode of service may not be an effective population-level strategy for lowering smoking prevalence. Future research might explore how to increase the helpfulness of the service through integration with online support and whether the service may be best promoted to certain subgroups of smokers. The results of this study are also in accordance with accumulating evidence that some cessation aids - such as self-help materials [32] and natural therapies [33] - have only marginal helpfulness. Interestingly, of the 105 individuals in this study who reported that 'something else' helped them quit, about 
Table 3 Logistic models predicting recent quitters' use of cold turkey, NRT, GP advice, and prescribed medication

\begin{tabular}{|c|c|c|}
\hline Outcome & Predictor & OR $(95 \% \mathrm{Cl})$ \\
\hline Cold turkey & Age (yrs) & \\
\hline \multirow[t]{9}{*}{$(n=1028)$} & $51+$ & 1 \\
\hline & $31-50$ & $1.18(0.87-1.59)$ \\
\hline & $18-30$ & $2.28(1.55-3.35)$ \\
\hline & SES & \\
\hline & Low & 1 \\
\hline & Mod-high & $1.42(1.08-1.87)$ \\
\hline & Quit duration & \\
\hline & $0-6$ mths & 1 \\
\hline & 7-12 mths & $1.66(1.24-2.22)$ \\
\hline NRT & Age (yrs) & \\
\hline \multirow[t]{6}{*}{$(n=1067)$} & $18-30$ & 1 \\
\hline & $31-50$ & $2.26(1.55-3.30)$ \\
\hline & $51+$ & $2.33(1.58-3.44)$ \\
\hline & Quit duration & \\
\hline & 7-12 mths & 1 \\
\hline & $0-6$ mths & $1.39(1.04-1.85)$ \\
\hline GP advice & Age (yrs) & \\
\hline \multirow[t]{9}{*}{$(n=1054)$} & $18-30$ & 1 \\
\hline & $31-50$ & $1.99(1.30-3.06)$ \\
\hline & $51+$ & $3.21(2.10-4.91)$ \\
\hline & Education & \\
\hline & High & 1 \\
\hline & Low & $1.56(1.16-2.09)$ \\
\hline & Quit duration & \\
\hline & 7-12 mths & 1 \\
\hline & $0-6$ mths & $1.37(1.003-1.86)$ \\
\hline Prescribed medication & Age (yrs) & \\
\hline \multirow[t]{9}{*}{$(n=1055)$} & $18-30$ & 1 \\
\hline & $31-50$ & $2.44(1.34-4.43)$ \\
\hline & $51+$ & $3.70(2.05-6.67)$ \\
\hline & Education & \\
\hline & High & 1 \\
\hline & Low & $1.69(1.16-2.47)$ \\
\hline & Quit duration & \\
\hline & 7-12 mths & 1 \\
\hline & $0-6$ mths & $2.34(1.52-3.61)$ \\
\hline
\end{tabular}

Note. $\mathrm{OR}=$ Odds Ratio; $\mathrm{Cl}=$ Confidence Interval; Edu = Education (low $=$ less than Year 12 , high $=$ some or completed tertiary); SES = socio-economic status.

$40 \%$ of their responses related to advice, support or urging from family and friends. Other researchers have noted this [3], and it supports recent research indicating that conversations with family and friends might play an important role in the quitting process, and that anti-smoking media campaigns might be helpful in stimulating these kinds of conversations $[34,35]$.

Strengths of this study are the relatively large sample of recent quitters and the breadth of cessation methods included. However, it relied on retrospective recall of cessation methods, with the possibility that memories of quitting could have become distorted over time. We found an association between duration of quitting and use of cold turkey methods. There are several potential explanations for this. The first is that individuals who have more durable cessation are more likely to have used cold turkey methods, perhaps because they smoked occasionally and did not need more intensive cessation assistance. An alternative explanation is that the longer the duration of cessation, the more likely it is that individuals forget about other methods which may have been helpful such as NRT and instead recall their personal efforts. However, we prompted respondents with each of the different cessation methods in an effort to capture all methods used, rather than simply 'top-ofmind' recall. Our analyses indicated no association between perceived helpfulness of each reported cessation method and duration of quitting. The somewhat low response rate of this survey may have led to some unknown bias, though this rate is comparable with other population surveys which use similarly conservative estimates both in Australia [36] and the U.S. [37]. Further, the rates of use of the various cessation methods in this study were similar to that in other surveys of NSW smokers $[4,8]$, suggesting that the sample is representative in this respect. We also note that the survey did not include questions about adherence to any treatment guidelines, details about prior cigarette consumption or quitting history.

\section{Conclusion}

Current U.S. Clinical Practice Guidelines recommend that all smokers be advised to use medication and behavioural treatment in quitting [23]. Chapman and Mackenzie raise a potential negative consequence of all smokers being imbued with the message that serious cessation efforts require treatment: they might become disempowered and inhibited in their quit attempts through self-defeating fatalism [25]. Our study confirms that many smokers quit without pharmacological or other interventions and that methods such as quitting cold turkey or gradual reduction are as likely to be rated as helpful as assisted cessation methods. This finding highlights the opportunity for presenting this empowering message to smokers who are ready to try to quit. At the same time, we acknowledge the importance of providing effective support to smokers who need it particularly more heavily nicotine dependent individuals. In addition, population-level strategies such as smoke-free environments [38], graphic pack warnings [39], increased cigarette prices [24], and well funded and effective media campaigns $[7,24]$, must continue to be emphasised, as they are important sources of motivation and support for smokers - particularly young adults - who make less use of conventional forms of quitting assistance. 


\section{Funding}

This work was not supported by any funding.

\section{Acknowledgements}

The authors thank Professor Melanie Wakefield for her suggestions for further analysis of the data, as well as Professor Simon Chapman, Anita Dessaix and James Kite for their comments on the manuscript. SEIFA data was accessed through the Health Outcomes Information and Statistics Toolkit (HOIST) system, a data access, analysis and reporting facility established and operated by the Centre for Epidemiology and Research, Population Health Division, NSW Department of Health.

\section{Author details}

${ }^{1}$ Monitoring, Evaluation and Research Unit, Cancer Institute NSW, Level 9, 8 Central Avenue, Australian Technology Park, Eveleigh NSW 2015, Australia. ${ }^{2}$ Cancer Prevention Division, Cancer Institute NSW, Level 9, 8 Central Avenue, Australian Technology Park, Eveleigh NSW 2015, Australia. ${ }^{3}$ Sydney School of Public Health, The University of Sydney, Edward Ford Building, NSW 2006, Australia.

\section{Authors' contributions}

$\mathrm{WH}$ led the design, conducted the analysis and led the interpretation of results, and contributed to the first draft of the article. SD drafted the article. DP managed the data and oversaw the analysis. TC conceived the study. All authors aided in the interpretation of the results, as well as critically reviewed and approved the final article.

\section{Competing interests}

The authors declare that they have no competing interests.

Received: 7 March 2011 Accepted: 27 July 2011 Published: 27 July 2011

\section{References}

1. Begg S, Vos T, Barker B, Stevenson C, Stanley L, Lopez A: The burden of disease and injury in Australia 2003. PHE 82. Canberra: Australian Institute of Health and Welfare; 2007.

2. Danaei G, Ding EL, Mozaffarian D, Taylor B, Rehm J, Murray CJL, Ezzati M: The preventable causes of death in the United States: Comparative risk assessment of dietary, lifestyle, and metabollic risk factors. PLoS Medicine 2009, 6(4):e1000058.

3. Shiffman S, Brockwell SE, Pillitteri JL, Gitchell JG: Use of smokingcessation treatments in the United States. Am J Prev Med 2008, 34(2):102-111.

4. Cancer Institute NSW: New South Wales Smoking and Health Survey 2009. Sydney, Australia: Cancer Institute NSW; 2009.

5. Hughes JR, Keely J, Naud S: Shape of the relapse curve and long-term abstinence among untreated smokers. Addiction 2004, 99(1):29-38.

6. Cokkinides VE, Ward E, Jemal A, Thun MJ: Under-use of smoking-cessation treatments: Results from the National Health Interview Survey, 2000. Am J Prev Med 2005, 28(1):119-122.

7. Biener L, Reimer R, Wakefield M, Szczypka G, Rigotti N, Connolly G: Impact of smoking cessation aids and mass media among recent quitters. Am J Prev Med 2006, 30(3):217-224.

8. Doran CM, Valenti L, Robinson M, Britt H, Mattick RP: Smoking status of Australian general practice patients and their attempts to quit. Addict Behav 2006, 31:758-766.

9. Zhu SH, Melcer T, Sun J, Rosbrook B, Pierce JP: Smoking cessation with and without assistance: A population-based analysis. Am J Prev Med 2000, 18(4):305-311.

10. Walsh RA, Paul CL, Tzelepis F, Stojanovski E: Quit smoking behaviours and intentions and hard-core smoking in New South Wales. Health Promotion Journal of Australia 2006, 17(1):54-60.

11. Fiore MC, Novotny TE, Pierce JP, Giovino GA, Hatziandreu EJ, Newcomb PA, Surawicz TS, Davis RM: Methods used to quit smoking in the United States. Do cessation programs help? J A M A 1990, 263(20):2760-2765.

12. Solberg LI, Asche SE, Boyle R, McCarty MC, Thoele MJ: Smoking and cessation behaviors among young adults of various educational backgrounds. Am J Public Health 2007, 97(8):1421-1426.
13. Stead LF, Perera R, Bullen C, Mant D, Lancaster T: Nicotine replacement therapy for smoking cessation. Cochrane Database of Systematic Reviews 2008, 1: CD000146.

14. Alberg AJ, Patnaik JL, May JW, Hoffman S, Gitchell J, Comstock G, Helzlsouer KJ: Nicotine replacement therapy use among a cohort of smokers. J Addict Dis 2005, 24:101-103.

15. Hymowitz N, Cummings KM, Hyland A, Lynn WR, Pechacek TF, Hartwell TD: Predictors of smoking cessation in a cohort of adult smokers followed for five years. Tob Control 1997, 6(Suppl 2):S57-62.

16. American Association for Public Opinion Research: Standard definitions: final dispositions of case codes and outcome rates for surveys Lenexa, Kansas: AAPOR; 2008.

17. Australian Bureau of Statistics: Population by age and sex, Australian states and territories, June 2006. Canberra: Australian Bureau of Statistics; 2007.

18. Australian Bureau of Statistics: 2006 census of population and housing: Socio-economic indexes for area's (SEIFA). Canberra, Australia: Commonwealth of Australia; 2008.

19. Dillon WR, Madden TJ, Firtle NH: Marketing Research in a Marketing Environment Burr Ridge, Illinois: Irwin; 1994.

20. Hosmer DW, Lemeshow S: Applied logistic regression. 2 edition. New York: Wiley \& Sons; 2000.

21. SPSS Inc.: SPSS For Windows Version 15. Chicago, IL: SPSS, Inc; 2005.

22. Hyland A, Li Q, Bauer JE, Giovino GA, Steger C, Cummings KM: Predictors of cessation in a cohort of current and former smokers followed over 13 years. Nicotine \& Tobacco Research 2004, 6(3):S363-369.

23. Fiore MC, Bailey WC, Cohen SJ, Dorfman SF, Goldstein MG, Gritz ER, Heyman RB, Holbrook J, Jaen CR, Kottke TE, et al: Treating tobacco use and dependence: 2008 update. Clinical practice guideline. Rockville MD: U.S. Department of Health and Human Services, Public Health Service; 2008.

24. Wakefield MA, Durkin S, Spittal M, Siahpush M, Scollo M, Simpson JA, Chapman S, White V, Hill D: Impact of tobacco control policies and mass media campaigns on monthly adult smoking prevalence. Am J Public Health 2008, 98(8):1443-1450.

25. Chapman S, Mackenzie R: The global research neglect of unassisted smoking cessation: causes and consequences. PLoS Medicine 2010, 7(2): e1000216.

26. Young JM, Ward JE: Implementing guidelines for smoking cessation advice in Australian general practice: opinions, current practices, readiness to change and perceived barriers. Fam Pract 2001, 18(1):14-20

27. Strecher VJ, Shiffman S, West R: Randomized controlled trial of a webbased computer-tailored smoking cessation program as a supplement to nicotine patch therapy. Addiction 2005, 100(5):682-688.

28. Cobb N: Online consumer search strategies for smoking-cessation information. Am J Prev Med 2010, 38(3 Suppl):S429-S432.

29. Keller PA, Feltracco MA, Bailey LA, Li Z, Niederdeppe J, Baker TB, Fiore MC: Changes in tobacco quitlines in the United States, 2005-2006. Preventing Chronic Disease: Public Health Research, Practice, and Policy 2010, 7(2):1-6.

30. Miller CL, Wakefield M, Roberts L: Uptake and effectiveness of the Australian telephone Quitline service in the context of a mass media campaign. Tob Control 2003, 12(Suppl 2):ii53-ii58.

31. Kaufman A, Auguston E, Davis K, Finney Rutton LJ: Awareness and use of tobacco quitlines: Evidence from the Health Information National Trends Survey. Journal of Health Communication 2010, 15(Suppl 3):264-278.

32. Lancaster T, Stead LF: Self-help interventions for smoking cessation. Cochrane Database Systematic Review 2005, 3:CD001118.

33. White AR, Rampes $H$, Campbell $\mathrm{J}$ : Acupuncture and related interventions for smoking cessation. Cochrane Database of Systematic Reviews 2006, 1: CD000009.

34. Dunlop SM, Wakefield M, Kashima Y: The contribution of anti-smoking advertising to quitting: intra- and inter-personal processes. Journal of Health Communication 2008, 13(3):250-266.

35. Durkin S, Wakefield M: Maximising the impact of emotive anti-tobacco advertising: effects of interpersonal discussion and program placement. Social Marketing Quarterly 2006, 12(3):3-14.

36. Thompson ME, Fong GT, Hammond D, Boudreau C, Driezen P, Hyland A, Borland R, Cummings KM, Hastings GB, Siahpush M, et al: Methods of the International Tobacco Control (ITC) Four Country Survey. Tob Control 2006, 15(Suppl 3):iii12-iii18.

37. Cantor D, Coa K, Crystal-Mansour S, Davis T, Dipko S, Sigman RRF: Health information national trends survey (HINTS) 2007: Final report. 2009. 
38. Fichtenberg CM, Glantz SA: Effect of smoke-free workplaces on smoking behaviour: systematic review. Br Med J 2002, 325:188.

39. Borland R, Yong HH, Wilson N, Fong GT, Hammond D, Cummings KM,

Hosking W, McNeill A: How reactions to cigarette packet health warnings influence quitting: findings from the ITC Four-Country survey. Addiction 2009, 104(4):669-675.

\section{Pre-publication history}

The pre-publication history for this paper can be accessed here: http://www.biomedcentral.com/1471-2458/11/592/prepub

doi:10.1186/1471-2458-11-592

Cite this article as: Hung et al.: Use and perceived helpfulness of

smoking cessation methods: results from a population survey of recent quitters. BMC Public Health 2011 11:592.

Submit your next manuscript to BioMed Central and take full advantage of:

- Convenient online submission

- Thorough peer review

- No space constraints or color figure charges

- Immediate publication on acceptance

- Inclusion in PubMed, CAS, Scopus and Google Scholar

- Research which is freely available for redistribution

Submit your manuscript at www.biomedcentral.com/submit 